KAWAKAMI J. 2015. Redução da adubação e doses e parcelamento de nitrogênio no crescimento e produtividade de batata. Horticultura Brasileira 33: 168-173. DOI - http://dx.doi.org/10.1590/S0102-053620150000200006

\title{
Redução da adubação e doses e parcelamento de nitrogênio no crescimento e produtividade de batata
}

\author{
Jackson Kawakami \\ UNICENTRO, Depto. Agronomia, C. Postal 3010, 85040-080 Guarapuava-PR; jkawakami@unicentro.br
}

\begin{abstract}
RESUMO
Neste trabalho verificou-se o efeito da redução de adubo e doses e parcelamento de nitrogênio $(\mathrm{N})$ no crescimento e produtividade de plantas de batata. Formou-se dois experimentos que foram implantados em janeiro ( $1^{\circ}$ experimento $)$ e novembro $\left(2^{\circ}\right.$ experimento $)$ de 2006 em Guarapuava-PR, utilizando-se a cultivar Ágata. No $1^{\circ}$ experimento, testaram-se três tratamentos com menores quantidades de fertilizantes e uma testemunha, simulando a adubação padrão da região, em blocos ao acaso com 4 repetições. No $2^{\circ}$ experimento, avaliou-se doses (3) e parcelamento (com e sem) de nitrogênio $(\mathrm{N})$, em um esquema fatorial 3 x 2 em blocos ao acaso com 3 repetições. Em ambos os experimentos coletou-se plantas em três estádios de desenvolvimento: início do florescimento, máximo desenvolvimento vegetativo e após a maturação fisiológica (colheita). No início do florescimento, não se observou diferença em nenhum parâmetro analisado, tanto no $1^{\circ}$ quanto no $2^{\circ}$ experimento. Entretanto, no máximo crescimento vegetativo o índice de área foliar (IAF) e a massa seca (MS) da parte aérea foram maiores no tratamento testemunha no $1^{\circ}$ experimento, e o $\mathrm{N}$ fornecido em dose total na base de plantio resultou em plantas com maior IAF e MS de tubérculos no $2^{\circ}$ experimento. $\mathrm{Na}$ colheita, a testemunha produziu maior massa de tubérculos, principalmente pela maior produção de tubérculos de tamanho médio no $1^{\circ}$ experimento; a dose de $\mathrm{N}$ afetou negativamente a porcentagem de MS dos tubérculos e houve efeito da interação parcelamento e dose de $\mathrm{N}$ na massa de tubérculos, em que a menor dose de $\mathrm{N}$ foi beneficiada pelo parcelamento no $2^{\circ}$ experimento. Nas condições deste estudo a quantidade de fertilizante tradicionalmente utilizada pelos produtores, bem como a menor dose de N, parcelada metade no plantio e metade em cobertura, resultaram em altas produtividades.
\end{abstract}

Palavras-chave: Solanum tuberosum, adubação nitrogenada, fertilização, produção.

\begin{abstract}
Fertilizer reduction and nitrogen rates and splitting on growth and yield of potato

This study verified the effect of fertilizer reduction and nitrogen (N) rates and splitting on the growth and yield of potato plants. Two experiments were formed and were planted in January ( $\left(1^{\text {st }}\right.$ experiment $)$ and November ( $2^{\text {nd }}$ experiment) 2006 in Guarapuava, Paraná state, Brazil, using cultivar Agata. In the $1^{\text {st }}$ experiment, three treatments were tested with smaller amount of fertilizer compared with the control, which simulated the traditional fertilization, in randomized blocks with 4 replications. In the $2^{\text {nd }}$ experiment, rates (3) and splitting (with and without) of nitrogen $(\mathrm{N})$ were evaluated, in $3 \times 2$ factorial scheme in randomized blocks with 3 replications. In both experiments, plants were collected at three growth stages: beginning of flowering, maximum shoot growth and after physiological maturity (harvest). At the beginning of flowering, no difference in any analyzed parameters was observed in both experiments. However, at the maximum shoot growth, leaf area index (LAI) and shoot dry weight (DW) were higher in control in the $1^{\text {st }}$ experiment, and $\mathrm{N}$ applied totally at planting resulted in plants with higher LAI and tuber DW in the $2^{\text {nd }}$ experiment. At harvest the control had higher tuber mass, mainly because of higher production of middle-sized tubers in the $1^{\text {st }}$ experiment; $\mathrm{N}$ rates negatively affected the percentage of tuber DW and interaction occurred with rate and splitting of $\mathrm{N}$ in tuber mass: the smallest rate of $\mathrm{N}$ was helped by splitting in the $2^{\text {nd }}$ experiment. In this study the traditional growers' fertilization and the smallest rate of $\mathrm{N}$, splitting half at planting and half at hilling, resulted in high tuber yield.
\end{abstract}

Keywords: Solanum tuberosum, fertilization, nitrogen fertilization, production.

(Recebido para publicação em 4 de agosto de 2014; aceito em 5 de fevereiro de 2015) (Received on August 4, 2014; accepted on February 5, 2015)

\begin{abstract}
A cultura da batata (Solanum tuberosum) foi plantada em cerca de 128 mil ha e produziu cerca de 3,5 milhões de toneladas no Brasil em 2013 (FAO, 2015). A região de Guarapuava tem tradição no cultivo desta solanácea, cultivando anualmente cerca de 2.000 ha com produção de cerca de 70 mil toneladas deste tubérculo (IBGE, 2015). Comparada com outras culturas com
\end{abstract}

que compete na região de Guarapuava, a lavoura comercial de batata apresenta um alto custo de produção. Dentre os itens do custo de produção de uma lavoura comercial de batata, os gastos com fertilizantes e batata semente costumam ser os itens mais dispendiosos da cultura. Tradicionalmente a lavoura de batata na região de Guarapuava-PR, é adubada utilizando-se o formulado
4-14-8 ou 4-16-8 na dose de 4,0 t/ha, independentemente da quantidade de nutrientes presentes no solo. Essa quantidade de fertilizante aplicada é superior à maioria das recomendações para a cultura (Comissão ..., 2004), entretanto Queiroz et al. (2013) concluíram que 4,2 $\mathrm{t} /$ ha do formulado 4-14-8 resulta na melhor produtividade técnica da cultura na região. Estudos sobre o desempenho 
de plantas de milho e feijão-de-vagem cultivados após a colheita da cultura da batata demonstraram o efeito residual das altas doses de fertilizante comumente empregados na cultura da batata (Kikuti et al., 2002). Devido ao alto investimento, os bataticultores optam pelas altas doses de fertilizantes para minimizar eventuais problemas de falta de nutrientes para a planta, fato que provocaria uma queda na produtividade e na rentabilidade financeira almejada. A alta quantidade de fertilizante aplicada, por seu lado, cria certos problemas de ordem biológica (Azeredo et al., 2004), econômica (Fontes et al., 2010) e ambiental (Shrestha et al., 2010), entre outros.

$\mathrm{O}$ nitrogênio $(\mathrm{N})$ é um dos nutrientes de maior impacto na produtividade das culturas, por estar relacionado diretamente à fotossíntese e ao crescimento vegetativo da planta (Yin et al., 2003). $\mathrm{O} \mathrm{N}$ na forma nítrica é rapidamente absorvido, mas também é facilmente lixiviado com a água, perdendo-se. $\mathrm{O}$ solo não fixa $\mathrm{N}$ e, por isso, pode ocorrer perda por lavagem, principalmente em solos arenosos, e também perda sob a forma gasosa (Shrestha et al., 2010), sendo que a cultura da batata é especialmente suscetível à perda de $\mathrm{N}$ (Jego et al., 2008). Outro fator que dificulta a dosagem correta é a eficiência da adubação nitrogenada. Tal eficiência pode ser definida como a quantidade de $\mathrm{N}$ proveniente do adubo absorvida pela planta, em relação à quantidade de $\mathrm{N}$ aplicado. A recuperação do N pela planta raramente excede $70 \%$ daquela aplicada e, na maior parte das culturas, atinge em média 50\%. Na cultura da batata essa recuperação é até menor, pois a absorção do N varia entre 13 e 45\%, sendo o restante de $\mathrm{N}$ lixiviado para as camadas profundas do solo (Song et al., 2014).

Há poucas informações sobre o efeito da aplicação de fertilizantes calculado levando-se em consideração os teores dos nutrientes presentes no solo e da dose e do parcelamento do $\mathrm{N}$ na cultura da batata. Dessa forma, o objetivo deste trabalho foi avaliar o efeito no crescimento e na produtividade de plantas de batata de adubação cuja quantidade e elementos levaram em consideração a quantidade de nutrientes existentes no solo e do parcelamento de $\mathrm{N}$, comparando-a com a adubação tradicional dos agricultores da região de Guarapuava.

\section{MATERIAL E MÉTODOS}

Os experimentos foram realizados no campus da Faculdade de Agronomia da Universidade Estadual do Centro-Oeste, na cidade de Guarapuava, sendo os plantios dos tubérculos de batata da cultivar Ágata realizados manualmente em ambos os experimentos, em 31 de janeiro (primeiro experimento) e 9 de novembro (segundo experimento) de 2006.

Os solos da camada de 0 a $20 \mathrm{~cm}$ antes da implantação dos tratamentos, do primeiro e segundo experimentos, apresentavam respectivamente as seguintes características químicas: $\mathrm{pH}$ $\left(\mathrm{CaCl}_{2}\right)=4,6$ e 5,7; matéria orgânica: 45,6 e 44,3 g/dm 3 ; P (Mehlich)=2,2 e $4,6 \mathrm{~g} / \mathrm{dm}^{3} ; \mathrm{K}=0,09$ e 0,$27 ; \mathrm{Ca}=2,3$ e 4,0; $\mathrm{Mg}=1,5$ e 2,$9 ; \mathrm{Al}=0,1$ e 0,$2 ; \mathrm{H}+\mathrm{Al}=$ 5,82 e 2,96 $\left(\mathrm{cmol}_{\mathrm{c}} / \mathrm{dm}^{3}\right)$. O elemento boro foi quantificado apenas no primeiro experimento (água quente) possuindo o teor de $0,13 \mathrm{mg} / \mathrm{dm}^{3}$.

No primeiro experimento o solo foi lavrado e corrigido com calcário calcítico $($ PRNT $=69,1 \%)$ para se atingir uma saturação de bases de $60 \%$ cerca de 1 mês antes do plantio e no segundo experimento o solo foi lavrado cerca de 5 meses antes do plantio, não necessitando de correção de acidez do solo.

No primeiro experimento utilizou-se o espaçamento de $75 \times 25 \mathrm{~cm}$, sendo que a parcela experimental $\left(13,5 \mathrm{~m}^{2}\right)$ constou de 6 linhas com 12 plantas/linha em densidade de plantio de 53.333 plantas/ ha, enquanto no segundo experimento adotou-se o espaçamento de 80 x 30 $\mathrm{cm}$, com parcela experimental $(23,04$ $\mathrm{m}^{2}$ ) de 6 linhas e 16 plantas, resultando em uma densidade de plantio de 41.667 plantas/ha.

Foram formados quatro tratamentos no primeiro experimento: Testemunha, simulando a quantidade tradicionalmente utilizada pelos bataticultores da região (4,1 t/ha do formulado 4-14-8) com 165, $578,330,495$ e $0,22 \mathrm{~kg} / \mathrm{ha}$ de $\mathrm{N}, \mathrm{P}_{2} \mathrm{O}_{5}$, $\mathrm{K}_{2} \mathrm{O}$, Ca e B, respectivamente; Redução, cujas doses foram calculadas segundo os teores dos nutrientes presentes no solo e a recomendação de adubação para a cultura (Comissão ..., 2004): 100, 350,250 e $361 \mathrm{~kg} /$ ha de $\mathrm{N}$ (ureia), $\mathrm{P}_{2} \mathrm{O}_{5}$ (superfosfato simples), $\mathrm{K}_{2} \mathrm{O}$ (cloreto de potássio) e $\mathrm{Ca}$ (superfosfato simples e gesso), respectivamente; Calcio, cujas doses foram as doses do tratamento Redução acrescidas de $510 \mathrm{~kg} / \mathrm{ha}$ de $\mathrm{Ca}$ (gesso), visando aumentar a baixa relação $\mathrm{Ca}: \mathrm{Mg}$ presente no solo; Boro, tratamento similar ao tratamento Calcio porém acrescido de $600 \mathrm{~g} / \mathrm{ha}$ de B (bórax), visando corrigir o baixo teor deste nutriente revelado pela análise de solo. Em todos os tratamentos, os adubos foram fornecidos de uma só vez, em linha imediatamente antes do plantio.

No segundo experimento, formou-se seis tratamentos, sendo três diferentes doses de N (ureia), fornecidas totalmente na linha no dia de plantio ou parcelados, metade da dose no plantio e a outra metade na linha, 15 dias após a emergência (DAE), época em que foi realizado a amontoa. Nos tratamentos denominados "100\%N", a adubação utilizada foi o que tradicionalmente se utiliza na região de Guarapuava para a cultura da batata, totalizando $164 \mathrm{~kg} / \mathrm{ha}$ de $\mathrm{N}$, parcelados ou não, além de 574 ; $328 ; 533 ; 369 ; 2,05$ e 10,6 kg/ha de $\mathrm{P}_{2} \mathrm{O}_{5}$, $\mathrm{K}_{2} \mathrm{O}, \mathrm{Ca}, \mathrm{S}, \mathrm{B}$ e $\mathrm{Zn}$, respectivamente. Nos demais tratamentos, buscou-se analisar o efeito da redução e da adição da quantidade de $\mathrm{N}$, sendo que os tratamentos " $75 \% \mathrm{~N}$ " representam 75\% da dose tradicional de $\mathrm{N}$, totalizando 123 $\mathrm{kg} /$ ha de $\mathrm{N}$, e os tratamentos " $150 \% \mathrm{~N}$ " representam $150 \%$ da adubação nitrogenada tradicional, totalizando $246 \mathrm{~kg} / \mathrm{ha}$ de $\mathrm{N}$, todo na base na linha de plantio ou parcelado na época da amontoa. As doses dos demais nutrientes foram as mesmas para todos os tratamentos.

Em ambos os experimentos, quatro plantas por parcela foram avaliadas em duas datas: início do florescimento aos 33 e 35 DAE e no máximo crescimento vegetativo aos 47 e 58 DAE, para o primeiro e segundo experimento, respectivamente. Nestas coletas, anotou-se a massa da matéria seca (MS, em estufa de aeração forçada a $70^{\circ} \mathrm{C}$ até massa constante) de tubérculos e MS da parte aérea (hastes + folhas). A área 
foliar foi calculada através de manipulação de fotos digitais de uma amostra de folhas realizada com o programa Image J (Abramoff et al., 2004) sendo então calculado, a área foliar total como produto da área foliar da amostra $\mathrm{x}$ MS de folhas/MS da amostra, e o índice de área foliar (IAF). Após a maturação fisiológica das plantas, coletou-se para cada parcela 12 plantas para a determinação do número, MS, massa da matéria fresca (MF) e porcentagem de MS dos tubérculos comerciais $(>45 \mathrm{~mm}$ de diâmetro). No primeiro experimento os tubérculos comerciais foram divididos em duas classes: $<200$ g (MM) e >200 $\mathrm{g}(\mathrm{GG})$. No segundo experimento, os tubérculos comerciais foram separados em duas classes: $<100 \mathrm{~g}(\mathrm{M})$ e $>100 \mathrm{~g}(\mathrm{G})$. A emergência e a maturação fisiológica foram determinadas visualmente na época em que $70 \%$ das plantas emergiram e amareleceram, respectivamente. Os tratos fitossanitários foram realizados conforme a prática comum adotada na região.

$\mathrm{O}$ esquema estatístico do primeiro experimento foi em blocos ao acaso com quatro repetições e no segundo experimento foi em blocos ao acaso em esquema fatorial $2 \times 3$, sendo os fatores: parcelamento ou não da adubação nitrogenada e as três doses de $\mathrm{N}$, com três repetições. Os dados foram agrupados e submetidos à análise de variância e, havendo significância, as médias foram separadas pelo teste de Tukey a $5 \%$ de probabilidade (JSPS, 11.5.0 for Windows).

\section{RESULTADOS E DISCUSSÃO}

No estádio de florescimento (33-35 DAE), não se observou diferença estatística significativa em nenhum dos parâmetros analisados entre os tratamentos, tanto no primeiro quanto no segundo experimento. Observou-se em média um IAF de 1,57 e 4,36; MS de tubérculos de 152 e $130 \mathrm{~g} / \mathrm{m}^{2}$; e MS da parte aérea de 121 e $273 \mathrm{~g} / \mathrm{m}^{2}$ para o primeiro e segundo experimento, respectivamente. Da interpretação destes resultados concluiu-se que nas condições deste estudo, as diferentes quantidades de fertilizantes disponibilizados às plantas foram sufi- cientes para o seu crescimento inicial e que o $\mathrm{N}$ não limitou o crescimento das plantas, mesmo na menor dose. Estes dados corroboram os dados de Yorinori (2003) que estudando a absorção de nutrientes e acúmulo de MS de plantas de batata afirma que a batateira absorve pouco nutriente durante o crescimento vegetativo, sendo que a MS acumulada até este estádio de crescimento varia de 2 a $5 \%$ da MS total.

No estádio de máximo crescimento vegetativo (47 e 58 DAE), não se observou diferença estatística entre os tratamentos do primeiro experimento no número e MS de tubérculos, o mesmo não acontecendo para IAF e MS da parte aérea, parâmetros em que plantas do tratamento Redução obtiveram menor valor do que plantas do tratamento Testemunha (Tabela 1). No segundo experimento, não se observou efeito da dose de $\mathrm{N}$ e da interação entre dose e parcelamento de $\mathrm{N}$ em nenhum parâmetro avaliado, mas constatou-se efeito do parcelamento da adubação nitrogenada no IAF e na MS de tubérculo, sendo que plantas que receberam o $\mathrm{N}$ todo na base produziram os maiores valores (Tabela 1). O menor IAF das plantas do tratamento Redução em comparação às plantas do tratamento Testemunha foi devido à menor MS da parte aérea das plantas do tratamento Redução em relação à Testemunha e este fato foi provavelmente devido à menor quantidade de $\mathrm{N}$ fornecido pelo tratamento Redução. De fato, Yin et al. (2003) constataram que a produção de folhas e hastes (parte aérea) é fortemente influenciada pela disponibilidade de $\mathrm{N}$ no solo à planta. $\mathrm{O}$ curto período entre o preparo do solo e o plantio (um mês), deve ter contribuído para a diminuição do $\mathrm{N}$ disponível às plantas que receberam menos $\mathrm{N}$, uma vez que neste sistema, restos vegetais não tiveram tempo suficiente para se decompor, retirando parte do $\mathrm{N}$ do solo para promover sua decomposição (Sharifi et al., 2009). Este fato é subsidiado pelos resultados do segundo experimento, em que o preparo antecipado do solo em cinco meses resultou em ausência de efeito da redução de $\mathrm{N}$ no crescimento da pare aérea das plantas. Desta forma demonstra-se que a utilização de menores doses de fertilizantes nitrogenados pode resultar em plantas vigorosas no máximo crescimento vegetativo, desde que o preparo do solo seja feito com antecedência quando houver restos vegetais que possam imobilizar

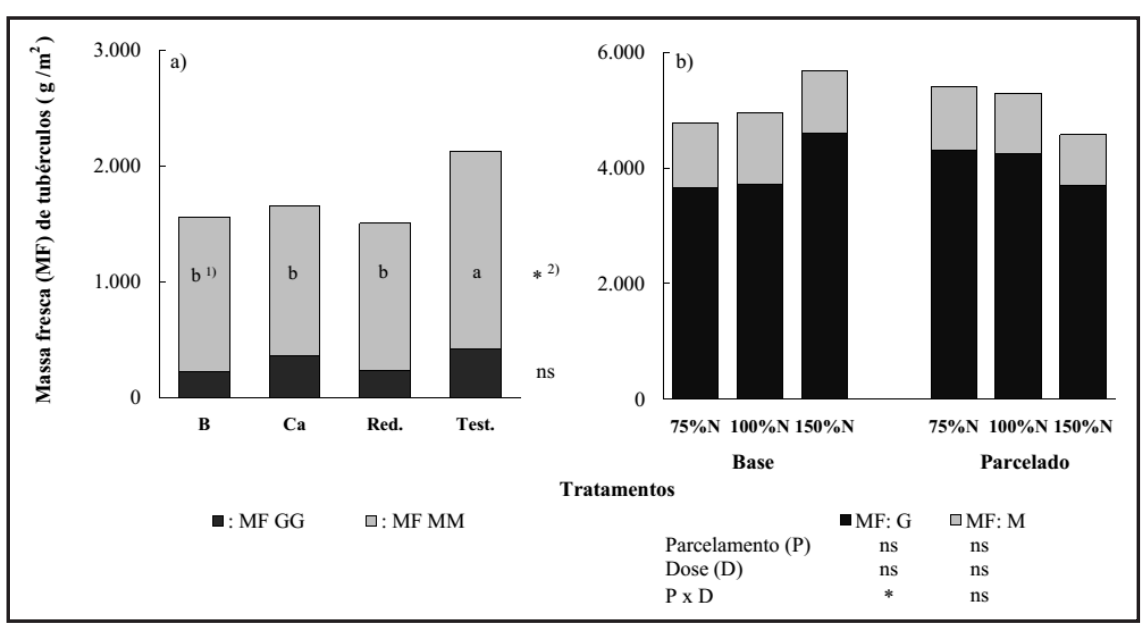

Figura 1. Produtividade comercial de tubérculos $(>45 \mathrm{~mm})$ de batata divididos em classes de tamanho, M, MM, G e GG $(<100,<200,>100 \mathrm{~g}$ e $>200 \mathrm{~g}$, respectivamente) oriundas de plantas submetidas a diferentes adubações (a) e diferentes doses e parcelamento de nitrogênio (b) \{potato comercial tuber yield ( $>45 \mathrm{~mm}$ ) classified in size classes, M, MM, G and $\mathrm{GG}(<100,<200,>100$ and $>200 \mathrm{~g}$, respectively) from plants with diferent fertilization (a) and rates and splitting of nitrogen (b) $\}$. ${ }^{1}$ Médias seguidas pela mesma letra não diferem estatisticamente entre si pelo teste de Tukey a 5\% (means followed by the same letter do not differ by Tukey test at $5 \%) ;{ }^{2} n s=$ diferença estatística não significativa $(\mathrm{p}>0,05)$ \{statistical difference not significant $(\mathrm{p}>0,05)\} ; *$ diferença estatística significativa a $5 \%(\mathrm{p}<0,05)$ \{significant difference at 5\% $(\mathrm{p}>0,05)\}$. Guarapuava, UNICENTRO, 2006. 
Tabela 1. Índice de área foliar (IAF), número e massa seca de tubérculos e massa seca da parte aérea (folhas + hastes) de plantas de batata submetidas a diferentes adubações aos 47 (Experimento 1) e 58 (Experimento 2) dias após emergência \{leaf area index (IAF), number and dry weight of tubers and dry weight of shoot (leaves + stem) of potato plants submitted to different fertilization at 47 (Experiment 1) and 58 (Experiment 2) days after emergence\}. Guarapuava, UNICENTRO, 2006.

\begin{tabular}{|c|c|c|c|c|}
\hline \multirow{2}{*}{ Tratamentos } & \multirow{2}{*}{ IAF } & \multirow{2}{*}{ Tubérculos/m² } & \multicolumn{2}{|c|}{ Massa seca $\left(\mathrm{g} / \mathrm{m}^{2}\right)$} \\
\hline & & & Tubérculos & Parte aérea \\
\hline \multicolumn{5}{|c|}{ Experimento 1} \\
\hline Boro & $1,39 b^{1}$ & 53 & 285 & $117 \mathrm{ab}$ \\
\hline Calcio & $1,79 \mathrm{ab}$ & 61 & 311 & $133 \mathrm{ab}$ \\
\hline Redução & $1,32 \mathrm{~b}$ & 50 & 296 & $106 \mathrm{~b}$ \\
\hline Testemunha & $2,28 \mathrm{a}$ & 58 & 374 & $141 \mathrm{a}$ \\
\hline Anova Exp. 1 & $* * 2$ & $\mathrm{~ns}$ & $\mathrm{~ns}$ & $*$ \\
\hline \multicolumn{5}{|c|}{ Experimento 2} \\
\hline \multicolumn{5}{|c|}{ Parcelamento (P) } \\
\hline Base & 6,26 & 67 & 711 & 371 \\
\hline Parcelado & 4,72 & 62 & 558 & 334 \\
\hline \multicolumn{5}{|l|}{ Dose \%N (D) } \\
\hline 75 & 5,22 & 65 & 598 & 340 \\
\hline 100 & 5,51 & 65 & 666 & 341 \\
\hline 150 & 5,74 & 65 & 638 & 376 \\
\hline \multicolumn{5}{|l|}{ Anova Exp. 2} \\
\hline$P$ & * & $\mathrm{ns}$ & $* *$ & $\mathrm{~ns}$ \\
\hline $\mathrm{D}$ & ns & $\mathrm{ns}$ & ns & $\mathrm{ns}$ \\
\hline$P \times D$ & ns & ns & ns & ns \\
\hline
\end{tabular}

${ }^{1}$ Médias seguidas pela mesma letra não diferem estatisticamente entre si pelo teste de Tukey a $5 \%$ (means followed by the same letter do not differ by Tukey test at $5 \%$ ); ${ }^{2} \mathrm{~ns}=$ diferença estatística não significativa $(\mathrm{p}>0,05)$ \{statistical difference not significant $(\mathrm{p}>0.05)\}, * * *=$ diferença estatística significativa a 5 e $1 \%$, respectivamente $(p<0,05$ e 0,01$)$ \{significant difference at 5 and $1 \%$, respectively $(\mathrm{p}<0.05$ and 0.01$)\}$.

parte do $\mathrm{N}$ fornecido.

Após a maturação fisiológica, na colheita final, no primeiro experimento, não se constatou diferença significativa entre os tratamentos no período entre a emergência das plantas e maturação fisiológica (período de crescimento), no número e na porcentagem de MS de tubérculos (Tabela 2). Entretanto, constatou-se diferença significativa na MF e MS de tubérculos, sendo que plantas dos tratamentos Redução, Calcio e Boro produziram menores MF e MS de tubérculos em relação às plantas do tratamento Testemunha. Esta diferença na produção de tubérculos foi, provavelmente, devido ao menor IAF das plantas daqueles tratamentos em relação ao tratamento Testemunha a partir da época da segunda avaliação tratamentos, foi o $\mathrm{N}$ (i.e., 165 e $100 \mathrm{~kg} /$ ha de $\mathrm{N}$ para o tratamento Testemunha e os demais, respectivamente).

A produtividade constatada no primeiro experimento de $21,3 \mathrm{t} / \mathrm{ha}$ na testemunha, e média de 15,7 t/ha nos demais tratamentos, é baixa se comparada à média de produtividade da região de Guarapuava no ano de 2006 (24,0 t/ha) (IBGE, 2015). Esta baixa produtividade foi devido ao baixo aumento na massa de tubérculos durante o período de máximo crescimento vegetativo aos $47 \mathrm{DAE}$ (Tabela 1) e a maturação fisiológica a cerca de 80 DAE (Tabela 2), e a causa deste baixo aumento neste período não é conhecida.

No segundo experimento, não se constatou efeito do parcelamento da adubação nitrogenada em nenhum dos parâmetros avaliados, sendo que em média produziu-se 51,1 t/ha (Tabela 2). Barcelos et al. (2007) também não encontraram efeito positivo do parcelamento do $\mathrm{N}$ na produtividade final de tubérculos, corroborando os resultados do segundo experimento. A alta porcentagem de argila (58\%) do solo da área experimental, aliada ao preparo antecipado do solo, provavelmente contribuíram para a ausência de efeito do parcelamento na produtividade final de tubérculos. De fato, Shillito et al. (2009) concluíram que o teor de argila no solo é um dos principais fatores que causam variação significativa nas respostas da adubação nitrogenada. Por outro lado, Al-Moshileh et al. (2005) observaram efeito positivo do parcelamento do $\mathrm{N}$ em três vezes até a dose de $300 \mathrm{~kg} / \mathrm{ha}$, enquanto Silva et al. (2009) observaram efeito positivo do parcelamento de $\mathrm{N}$ na dose total de $256 \mathrm{~kg} / \mathrm{ha}$ de $\mathrm{N}$, apenas na época das águas em solo arenoso.

As doses de $\mathrm{N}$ afetaram apenas a porcentagem de MS dos tubérculos, sendo que a maior dose resultou em tubérculos com menor porcentagem de MS. Resultados semelhantes foram encontrados por outros autores (Oliveira et al., 2006; Goffart et al., 2008) corroborando a informação de que altas doses de $\mathrm{N}$ podem afetar negativamente a qualidade dos tubérculos. A ausência de efeito das doses de $\mathrm{N}$ no segundo experimento corroboram com os resultados obtidos por Ferreira \& Gonçalves 
Tabela 2. Período entre a emergência e a senescência foliar (período de crescimento), número, massa fresca (MF) e seca (MS) e porcentagem de MS de tubérculos comerciais de batata (>45 mm) colhidos após a maturação fisiológica, submetidos a diferentes adubações \{time between emergence and foliar senescence (growing period), number, fresh weight (MF), dry weight (MS) and percentage of MS of commercial potato tuber $(>45 \mathrm{~mm})$ harvested after physiological maturity, submitted to different fertilization \}. Guarapuava, UNICENTRO, 2006.

\begin{tabular}{|c|c|c|c|c|c|}
\hline \multirow[t]{2}{*}{ Tratamentos } & \multirow{2}{*}{$\begin{array}{l}\text { Período de } \\
\text { crescimento }\end{array}$} & \multicolumn{3}{|c|}{ Tubérculos comerciais $\left(\mathrm{g} / \mathrm{m}^{2}\right)$} & \multirow{2}{*}{$\begin{array}{l}\text { MS } \\
(\%)\end{array}$} \\
\hline & & $n^{0}$ & MF & MS & \\
\hline \multicolumn{6}{|c|}{ Experimento 1} \\
\hline Boro & 81 & 23 & $1.554 \mathrm{~b}^{1}$ & $253 \mathrm{~b}$ & 16,3 \\
\hline Calcio & 80 & 25 & $1.652 \mathrm{~b}$ & $265 \mathrm{~b}$ & 16,0 \\
\hline Redução & 79 & 27 & $1.504 \mathrm{~b}$ & $238 \mathrm{~b}$ & 15,8 \\
\hline Testemunha & 81 & 31 & $2.129 \mathrm{a}$ & $349 \mathrm{a}$ & 16,3 \\
\hline Anova Exp. 1 & $\mathrm{~ns}^{2}$ & ns & $*$ & $*$ & ns \\
\hline \multicolumn{6}{|c|}{ Experimento 2} \\
\hline \multicolumn{6}{|c|}{ Parcelamento (P) } \\
\hline Base & 76 & 41 & 5.135 & 694 & 13,5 \\
\hline Parcelado & 77 & 39 & 5.093 & 688 & 13,5 \\
\hline \multicolumn{6}{|l|}{ Dose \%N (D) } \\
\hline 75 & 76 & 42 & 5.122 & 698 & $13,6 \mathrm{ab}$ \\
\hline 100 & 77 & 38 & 5.088 & 707 & 13,9 a \\
\hline 150 & 76 & 40 & 5.132 & 666 & $13,0 \mathrm{~b}$ \\
\hline \multicolumn{6}{|l|}{ Anova Exp. 2} \\
\hline $\mathrm{P}$ & ns & ns & ns & ns & ns \\
\hline $\mathrm{D}$ & ns & ns & ns & ns & $*$ \\
\hline$P \times D$ & ns & ns & $* *$ & $*$ & ns \\
\hline
\end{tabular}

${ }^{1}$ Médias seguidas pela mesma letra não diferem estatisticamente entre si pelo teste de Tukey a $5 \%$ (means followed by the same letter do not differ by Tukey test at $5 \%$ ); ${ }^{2} \mathrm{~ns}=$ diferença estatística não significativa $(\mathrm{p}>0,05)$ \{statistical difference not significant $(\mathrm{p}>0.05)\} ; * * *=$ diferença estatística significativa a 5 e $1 \%$, respectivamente $(\mathrm{p}<0,05$ e 0,01$)$ \{significant difference at 5 and $1 \%$, respectively $(\mathrm{p}<0.05$ and 0.01$)\}$.

(2007), porém Sangoi \& Kruise (1994), Coelho et al. (2010) e Ziadi et al. (2011) encontraram resposta em produtividade de plantas de batata até a dose de 100 , 150 e $300 \mathrm{~kg} / \mathrm{ha} \mathrm{de} \mathrm{N}$, respectivamente, e Silva et al. (2007) recomendam doses de 163 a $171 \mathrm{~kg} / \mathrm{ha}$ de $\mathrm{N}$, dependendo do cenário favorável ou desfavorável ao preço da batata.

Observou-se interação estatística significativa entre o parcelamento e as doses de $\mathrm{N}$ para a MS e MF de tubérculos (Tabela 2). Para os tratamentos $75 \% \mathrm{~N}$ e $100 \% \mathrm{~N}$, o parcelamento da adubação nitrogenada acarretou em médias em tubérculos maiores que aquelas fornecidas totalmente no plantio. Entretanto, no tratamento $150 \% \mathrm{~N}$, os maiores valores de MS e MF de tubérculos foram observados quando o $\mathrm{N}$ foi disponibili- zado às plantas em dose única no plantio. Esperava-se que o parcelamento do $\mathrm{N}$ do tratamento $150 \% \mathrm{~N}$ seria benéfico para a produtividade de tubérculos, uma vez que o aumento da dose de $\mathrm{N}$ aumenta a sua quantidade perdida por lixiviação (Shrestha et al., 2010; Song et al., 2014) e o parcelamento do $\mathrm{N}$ tende a diminuir sua perda para o solo.

Na Figura 1a, observa-se a produção de tubérculos por classe de tamanho após a senescência das plantas adubadas com diferentes doses de fertilizantes no primeiro (Figura 1a) e no segundo (Figura 1b) experimento. Nota-se que no primeiro experimento não houve diferença significativa quanto à produção de tubérculos da classe GG entre os tratamentos, porém, plantas do tratamento Testemunha produziram maior quanti- dade de tubérculos da classe MM que plantas dos demais tratamentos (Figura 1a). Desta forma, entende-se que a maior produtividade de tubérculos das plantas do tratamento Testemunha no primeiro experimento (Tabela 2) foi devido à maior produção de tubérculos de tamanho médio (Figura 1a) destas plantas.

No segundo experimento, observou-se interação significativa entre parcelamento e dose de $\mathrm{N}$ na produção de tubérculos grandes (G) (Figura 1b). Observa-se que a interação significativa observada para a produção comercial de tubérculos (Tabela 2), foi devido à interação no mesmo sentido observada para a produção dos tubérculos da maior classe (G) observada na Figura 1b. Desta forma, o parcelamento da adubação nitrogenada causou aumento da produção de tubérculos grandes para os tratamentos $75 \% \mathrm{~N}$ e $100 \% \mathrm{~N}$, mas teve efeito inverso no tratamento $150 \% \mathrm{~N}$. A maior produtividade comercial observada no segundo experimento foi de $56,9 \mathrm{t} / \mathrm{ha}$ no tratamento $150 \% \mathrm{~N}$ fornecido todo na base, sendo que no tratamento $75 \% \mathrm{~N}$ parcelado, observou-se uma produtividade de 54,0 t/ha, apenas 5\% inferior à maior produtividade. Desta forma, é evidente que o produtor deve levar em consideração a utilização da menor dose de $\mathrm{N}$ de forma parcelada, caso a operação de adubação em cobertura não onere e não dificulte demasiadamente $o$ manejo fitotécnico da cultura. Ademais, uma vez que a eficiência do uso do $\mathrm{N}$ pelas plantas diminui com o aumento do $\mathrm{N}$ mineral fornecido (Chloupek et al., 2004), alternativas para uma melhor eficiência no uso do N pela cultura através de cultivares mais eficientes, tecnologia de aplicação do fertilizante, entre outros, deveria ser preferencialmente utilizada em comparação ao aumento da dose de $\mathrm{N}$ fornecido (Shrestha et al., 2010).

Nas condições edafoclimáticas do presente estudo, a redução da quantidade de fertilizante tradicionalmente fornecida para o cultivo da batata na região de Guarapuava, mesmo acrescida de cálcio e boro, resultou em menor produtividade final, porém a utilização da menor dose de $\mathrm{N}(75 \% \mathrm{~N}, 120 \mathrm{~kg} / \mathrm{ha})$ parcelado metade no plantio e metade na amontoa, resulta na melhor opção econômica quando o preparo do solo é 
realizado de forma antecipada.

\section{AGRADECIMENTOS}

O autor agradece aos alunos de graduação do curso de Agronomia da UNICENTRO pelo auxílio na coleta dos dados.

\section{REFERÊNCIAS}

ABRAMOFF MD; MAGELHAES PJ; RAM SJ. 2004. Image processing with ImageJ. Biophotonics International 11: 36-42.

AL-MOSHILEH AM; ERREBHI MA; MOTAWEI MI. 2005. Effect of various potassium and nitrogen rates and splitting methods on potato under sandy soil and arid environmental conditions. Emirates Journal of Agricultural Science 17: 01-09.

AZEREDO BH; LIMA E; CASSINO PCR. 2004. Impacto dos nutrientes $\mathrm{N}$ e $\mathrm{K}$ e de açúcares solúveis sobre populações de Diabrotica speciosa (Coleoptera, Chrysomelidae) e Agrotis ípsilon (Lepidoptera, Noctuidae) na cultura da batata, Solanum tuberosum (Solanaceae). Revista Brasileira de Entomologia 48: 105-113.

BARCELOS DM; GARCIA A; MACIEL VAJ. 2007. Análise de crescimento da cultura da batata submetida ao parcelamento da adubação nitrogenada em cobertura, em um latossolo vermelho-amarelo. Ciência e Agrotecnologia 31: 21-27.

CHLOUPEK O; HRSTKOVA P; SCHWEIGERT P. 2004. Yield and its stability, crop diversity, adaptability and response to climate change, weather and fertilization over 75 years in the Czech Republic in comparison to some European countries. Field Crops Research 85: 167-190.

COELHO FS; FONTES PCR; PUIATTI M; NEVES JCL; SILVA MCC. 2010. Dose de nitrogênio associada à produtividade de batata e índices do estado de nitrogênio na folha. Revista Brasileira de Ciência do Solo 34: 1175-1183.

COMISSÃO DE QUÍMICA E FERTIILIDADE DO SOLO. 2004. Manual de adubação e calagem para os estados do Rio Grande do
Sul e de Santa Catarina. 10 ed. Porto Alegre: SBCS-NRS. 400p.

FAO. FAOSTAT. 2015. Disponível em http:// faostat3.fao.org/browse/Q/QC/E. Acessado em 05 de fevereiro de 2015.

FERREIRA TC; GONÇALVES DA. 2007. Crop-yield/water-use production functions of potatoes (Solanum tuberosum) grown under differential nitrogen and irrigation treatments in a hot, dry climate. Agricultural Water Management 90: 45-55.

FONTES PCR; BRAUN H; BUSATO C; CECON PR. 2010. Economic optimum nitrogen fertilization rates and nitrogen fertilization rate effects on tuber characteristics of potato cultivars. Potato Research 53: 167-179.

GOFFART JP; OLIVIER M; FRANKINET M. 2008. Potato crop nitrogen status assessment to improve $\mathrm{N}$ fertilization management and efficiency: past-present-future. Potato Research 51: 355-383.

IBGE. 2014. Sistema IBGE de recuperação automática - SIDRA. Disponível em http:// www.sidra.ibge.gov.br/bda/tabela/listabl. asp? $\mathrm{c}=1001 \& \mathrm{z}=\mathrm{p} \& \mathrm{o}=28$. Acessado em $5 \mathrm{de}$ fevereiro de 2015.

JEGO G; MARTÍNEZ M; ANTIGÜEDAD; LAUNAY M; SANCHEZ-PEREZ JM; JUSTES E. 2008. Evaluation of the impact of various agricultural practices on nitrate leaching under the root zone of potato and sugar beet using the STICS soil-crop model. Science of the Total Environment 394: $207-$ 221.

KIKUTI H; ANDRADE MJB; RAMALHO MAP; ABREU AFB. 2002. Viabilidade econômica da adubação adicional de genótipos de feijoeiro em relação ao resíduo de adubação da batata. Pesquisa Agropecuária Brasileira 37: 455-461.

NAVA G; DECHEN AR; IUCHI VL. 2007. Produção de tubérculos de batata-semente em função das adubações nitrogenadas, fosfatada e potássica. Horticultura Brasileira 25: 365-370.

OLIVEIRA VR; ANDRIOLO JL; BISOGNIN DA; PAULA AL; TREVISAN AP; ANTES RB. 2006. Qualidade de processamento de tubérculos de batata produzidos sob diferentes disponibilidades de nitrogênio. Ciência Rural 36: 660-663.

QUEIROZ LRM; KAWAKAMI J; MULLER
MM; OLIARI ICR; UMBURANAS RC; ESCHEMBACK V. 2013. Adubação NPK e tamanho de batata-semente no crescimento, produtividade e rentabilidade de plantas de batata. Horticultura Brasileira 31: 119-127.

SANGOI L; KRUSE ND. 1994. Doses crescentes de nitrogênio, fósforo e potássio e características agronômicas da batata em dois níveis de $\mathrm{pH}$. Pesquisa Agropecuária Brasileira 29: 1333-1343.

SHARIFI M; ZEBARTH BJ; PORTER A; BURTON DL; GRANT CA. 2009. Soil mineralizable nitrogen and soil nitrogen supply under two-year potato rotations. Plant and Soil 320: 267-279.

SHILLITO RM, TIMLIN DJ; FLEISHER D; REDDY VR; QUEBEDEAUX B. 2009. Yield response of potato to spatially patterned nitrogen application. Agriculture, Ecosystems and Environment 129: 107-116.

SHRESTHA RK; COOPERBAND LR; MACGUIDWIN AE. 2010. Strategies to reduce nitrate leaching into groundwater in potato grown in sandy soils: case study from North Central USA. American Journal of Potato Research 87: 229-244.

SILVA MCC; FONTES PCR; MIRANDA GV. 2007. Modelos estatísticos para descrever a produtividade de batata em função da adubação nitrogenada. Horticultura Brasileira 25: 360-364.

SILVA MCC; FONTES PCR; MIRANDA GV. 2009. Índice SPAD e produção de batata, em duas épocas de plantio, em função de doses de nitrogênio. Horticultura Brasileira 27: 17-22.

SONG C; GUAN Y; WANG D; ZEWUDIE D; LI FM. 2014. Palygorskite-coated fertilizers with a timely release of nutrients increase potato productivity in a rain-fed cropland. Field Crops Research 166: 10-17.

YIN X; LANTINGA A; SCHAPENDONK HCM; ZHONG X. 2003. Some quantitative relationships between leaf area index and canopy nitrogen content and distribution. Annals of Botany 91: 893-903.

YORINORI GT. Curva de crescimento e acúmulo de nutrientes pela cultura da batata $\mathrm{c} v$. 'Atlantic'. 2003. Piracicaba: ESALQ. 66p (Dissertação mestrado).

ZIADIN; GRANT C; SAMSON N; NYIRANEZA J; BÉLANGER G; PARENT LE. 2011. Efficiency of controlled-released urea for potato production system in Quebec, Canada. Agronomy Journal 103: 60-66. 